\title{
Difference in Number of Electrons in Inner Shells of Charged or Uncharged Elements in Organic and Inorganic Chemistry: Compatibility with the Even-Odd Rule
}

\author{
Geoffroy Auvert \\ Grenoble Alpes University, Grenoble, France \\ Email: geoffroy.auvert@grenoble-inp.org
}

How to cite this paper: Auvert, G. (2017) Difference in Number of Electrons in Inner Shells of Charged or Uncharged Elements in Organic and Inorganic Chemistry: Compatibility with the Even-Odd Rule. Open Journal of Physical Chemistry, 7, 72-88. https://doi.org/10.4236/ojpc.2017.72006

Received: March 1, 2017

Accepted: May 14, 2017

Published: May 17, 2017

Copyright $\odot 2017$ by author and Scientific Research Publishing Inc. This work is licensed under the Creative Commons Attribution International License (CC BY 4.0).

http://creativecommons.org/licenses/by/4.0/

\begin{abstract}
The recently introduced even-odd rule has been shown to successfully represent chemical structures of ions and molecules. While comparing available drawings in the scientific literature with the list of compounds predicted by the even-odd rule, it became however obvious that existing compounds are fewer than expected. Several predicted compounds involving many covalent bonds have apparently never been experimentally observed. Neutral oxygen for instance is expected to have 6 valence electrons, whereas oxygen can only build a maximum of two bonds, as in water. This specificity is observed for elements in the top-right corner of the periodic table. For compounds to contain only single covalent bonds, and thus follow the even-odd rule, further explanations are necessary. The present paper proposes that those specific elements experience a transfer of electrons from the valence shell into the inner shell, making them unavailable for further bonding. These elements will be described as organic, hereby providing a clear and hopefully unifying definition of the term. In opposition, inorganic elements have a constant inner shell no matter their electrical state or the number of bonds they maintain. More than 70 compounds involving 11 elements of the main group are studied, revealing a progression from fully inorganic elements at the left of the periodic table to fully organic elements. The transition between inorganic or organic elements is made of few elements that take an organic form when negatively charged; they are labelled semi-organic. The article concludes that the fully organic elements of the main group are Oxygen and Fluorine, whereas semiorganic elements are more numerous: $\mathrm{C}, \mathrm{N}, \mathrm{S}, \mathrm{Cl}, \mathrm{Se}, \mathrm{Br}$ and $\mathrm{I}$. Thus, the even-odd rule becomes fully compatible with scientific knowledge of compounds in liquid or gaseous phase.
\end{abstract}




\section{Keywords}

Organic, Inorganic, Element, Chemistry, Even-Odd, Rule, Inner Shell, Bond, Single Bond, Charge, State

\section{Introduction}

The first rule to describe the organization of electrons in atoms belonging to a compound was the octet rule in the 1920s [1] [2] [3]. This rule imposes that chemically bonded elements should at all time be surrounded by eight electrons. It perfectly suited molecules like methane, ammonia, water and hydrogen fluoride. To render this rule compatible with other compounds like dioxygen, dinitrogen or benzene, multi-bonded connections were imagined [4] [5]. In the 2000s however, R. J. Gillespie already noticed that this rule remains mainly applicable to the few elements composing these specific molecules [6] [7].

In an attempt to have a unified rule applicable to a wider number of molecules, a new rule named the even-odd rule was recently proposed [8]. Following articles have investigated additional ions and molecules and confirmed the applicability of the even-odd rule to a great number of compounds [9] [10] [11]. A side effect was that this rule predicted the existence of molecules that were neither referenced by Greenwood [12] nor by other scientific data references [13] [14] [15]. A pattern was identified showing that these inexistent compounds would more often occur at the top right of the periodic table [15] [16].

Starting with this observation, the present paper proposes an explicit definition of what makes an element organic or inorganic. Building on the electrons configuration around the nucleus specific to the even-odd rule, it associates an organic state to a surplus of electrons pairs in the inner shell. It also introduces the concept of semi-organic elements.

Four important constrains should be remembered throughout the following: 1) Studied elements belong to the main group of the periodic table; 2) Chemical compounds are ions and molecules in gaseous or liquid phases; 3) Two neighbor elements in a compound are never connected through more than one single covalent bond [10]; 4) Elements cannot bear more than a single charge [17] [18].

On notation and terminology, the reader should also take good notice that ions or molecules bearing an overall charge will be written after these examples: $\mathrm{H} 2 \mathrm{O}$ for neutral water, $\mathrm{H} 3 \mathrm{O}(+)$ for positive water ions and $\mathrm{OH}(-)$ for negative water ions [8] [9] [10] [11].

The software used to draw ions and molecules is Chemsketch [19].

\section{Structural Arrangements of the Electrons around the Nucleus}

There are two different ways to represent the arrangement of electrons around the nucleus of an atom. The first one, as seen in the periodic table, considers the atom as a stand-alone atom isolated from any other atoms. It identifies the total 
number of electrons and the number of electrons available for bonding. By contrast, the alternative method presented in this article is to consider elements as part of a compound, i.e. connected to other atoms. Here, the electronic structure is composed of three electrons shells including electrons involved in chemical bonds.

Both electronic representations are described below in greater details.

\subsection{Electronic Structure as Represented in the Periodic Table}

The periodic table follows specific codes, still used by modern chemists. Each element of the periodic table is represented by one or two letters, the acronym of the element name. Two numbers complete the name of each element. The greatest number is the total number of electrons of the element. The smallest number is the valence number, indicating the number of electrons that may be involved in chemical bonds. With this description, only two electrons shells are defined: the inner shell and the valence shell. The number of electrons in the inner shell is equal to the difference between the total number of electrons and the valence number of the element. The inner shell is filled with an even number of electrons.

In most rows of the main group in the periodic table, the inner shell is constant all along the row. In this main group, elements are ordered in 8 columns and valence numbers range from 1 to 8 . The column number of the element is equal to the number of electrons in the valence shell: Boron, element of column 3 , has for instance three electrons in the valence shell.

\subsection{Electronic Structure of an Element in a Compound as a Base for the Even-Odd Rule}

While the periodic table considers atoms in a mostly virtual state, unconnected to any other atom, the approach of the even-odd rule is to consider the element in situ, connected to other elements in the context of a chemical compound. The representation of an electronic structure must then take chemical bonds into account [11].

In the even-odd model, the electronic structure is composed of three shells: an inner shell, an inactive shell and a covalent shell:

The covalent shell is composed of electrons involved in covalent bonds. In dihydrogen, for instance, one covalent bond interconnects two hydrogen atoms and each has one electron in its own covalent shell [11].

The inactive shell, located inside the covalent shell, contains electrons pairs that are not currently involved in any covalent bonds but are available if needed.

The inner shell contains the remaining electrons that cannot participate in any bonds. Composed of an even number of electrons, it is mostly equal to the inner shell calculated from the periodic table. The exceptions are the subject of the present article and are detailed in Chapter 4.

To keep track of the electronic structure of an element in a compound, a specific notation is used in the following and illustrated below. From left to right: 
the number of electrons in the inner shell, the number of electrons in the inactive shell and the number of electrons in the covalent shell.

\section{Boron}

Element in boron monofluoride $\mathrm{BF}$ in the gas phase [15]

\section{Inner shell}

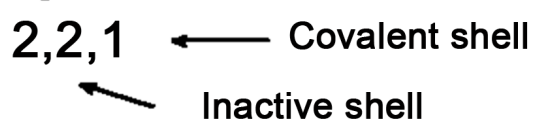

This example illustrates the electronic structure of Boron in a BF compound. The first two numbers are even, i.e. these shells contain electrons pairs. The third number gives the number of electrons located in the covalent shell. In $\mathrm{BF}$, one electron belongs to the boron covalent shell and one electron belongs to the fluorine covalent shell. Together, they form one covalent bond between $\mathrm{B}$ and $\mathrm{F}$.

The three numbers of the series inevitably add up to the total number of electrons of the element (here equal to 5 for boron in BF molecules).

\section{The Even-Odd Rule}

In this chapter, the main characteristics of the even-odd rule are summarized and illustrated with a charged boron atom.

\subsection{Charge States and the Effective Valence Number}

In the following, we will use the term "state" to designate the electrical state of an element. Since the even-odd rule limits elements to bearing a single charge or none [10], elements can only have three states: positive, neutral or negative. The state directly relates to the number of electrons of the element.

Derived from the known valence number from the periodic table, the Effective Valence Number (Ef.V.N.) depends on the state, i.e. the presence or the absence of one electron, as follows:

- In a neutral state, an element has an Ef.V.N. equal to the valence number: no electrons are added or removed.

- In a positive state, an electron is missing and the Ef.V.N. is the valence number decreased by one.

- In a negative state, an electron is added and the Ef.V.N. is the valence number increased by one.

\subsection{Number of Bonds and Inactive Shell}

It is important here to recall that the even-odd rule also imposes that two neighbor atoms in a compound can only be interconnected by a single covalent bond [10].

The even-odd rule is characterized by a representation of elements surrounded with several features: 1) three numbers, 2) a state (positive, neutral or negative), and 3) the number of covalent bonds illustrated by line segments.

For example, one would represent a boron atom with two bonds in a positive state as shown below: 


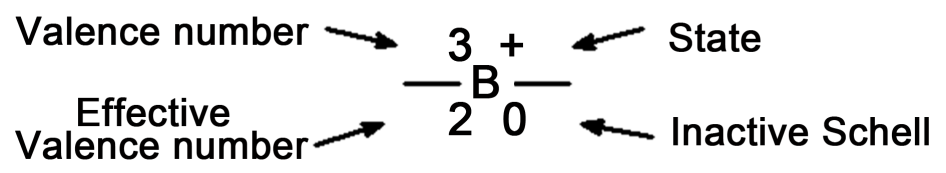

The upper left number is as defined by the valence number of the element. The upper right symbol indicates the state (positive $(+)$, neutral or negative $(-)$ ). The lower left number is the effective valence number (Ef.V.N.) calculated earlier.

The number of possible bonds is derived from the parity of the valence number and the state:

For an atom with an even number of electrons, the number of bonds is:

-In neutral state, even ranging from 0 up to the calculated Ef.V.N.

-In a charged state, odd ranging from 1 up to the Ef.V.N.

For an atom with an odd number of electrons, the number of bonds is:

-In neutral state, odd ranging from 1 up to the Ef.V.N.

-In a charged state, even ranging from 0 up to the Ef.V.N.

In other words, an element always erects number of bonds that has the same parity than its Ef.V.N.

The lower right number is the even number of electrons in the inactive shell; these are electrons that stand ready to be involved in covalent bonds. It is even and calculated by subtracting the number of bonds from the Ef.V.N. (lower left) of the element.

Another example: hydrogen has, in the periodic table, a valence number of 1 . For ion $\mathrm{H}(-)$, in a negative state, the Ef.V.N. is 2. It can therefore erect 0 or 2 bonds.

\section{Comparing Inorganic, Organic and Semi-Organic Elements}

\subsection{Three Sub-Groups for Elements of the Main Group}

The present article proposes that elements of the main group can be classified into 3 sub-groups. The first sub-group is composed of 20 elements, for which the number of electrons in the inner shell is calculated as usual from the periodic table. Elements in this sub-group are defined as inorganic. The second sub-group is composed of elements with an inner shell containing more electrons than expected from the periodic table. Elements in this sub-group are designated as organic. The third sub-group is composed of elements whose organic or inorganic condition is state dependent.

The sub-groups composition is:

- Organic. Oxygen and Fluorine are the only elements fully organic

- Semi-organic 7 elements compose this sub-group-C, N, S, Cl, Se, Br and I.

- Inorganic. the 20 elements composing this sub-group are neither organic nor semi-organic. In this paper, Hydrogen and Antimony will illustrate this subgroup.

Note that since noble gases do not bound with other elements, they do not belong to any of these sub-groups. 
The eleven elements named above will be studied in the present paper, illustrating all 3 sub-groups. Their electronic structures are carefully described in Chapter 5.

\subsection{Valence Number for Inorganic, Organic and Semi-Organic Elements in Compounds}

As opposed to earlier definitions of on the even-odd rule, in which the valence number is directly issued from the periodic table, the present paper states that the valence number now depends on the sub-group the element belongs to:

- In an inorganic element, the valence number does not depend on the state and is equal to the valence number obtained from the periodic table.

- In an organic element, the number of electrons that could be involved in bonding is not equal to the valence number from the periodic table but always smaller. We could name it the organic valence number. In that case, pairs of electrons have moved into the inner shell. The number of pairs in the inner shell is consequently higher than from the periodic table.

- A semi-organic element is organic in its negative state and inorganic in its positive state. The neutral state can be either and depends on the element location in the periodic table.

\subsection{Effective Valence Number for Inorganic, Organic and Semi-Organic Elements in Compounds}

Since the valence number is influenced by the sub-group it belongs to, the effective valence number obviously also. This makes the Ef.V.N. of an element dependent on two parameters: the state and the subgroup of the considered element.

Chapter 5 describes applications of the even-odd rule depending on both criteria.

\section{Applications}

\subsection{Examples of Two Inorganic Elements}

Inorganic elements have a valence number directly obtained from the periodic table. The following example shows an aluminium atom in a negative state and with two bonds (not a double bond). It possesses 13 electrons when neutral, here 14. They are distributed in the electrons shells: 10 electrons in the inner shell, 2 in the inactive shell and 2 in the covalent shell. Each electron of the covalent shell is engaged in a separate covalent bond with an electron from another atom.
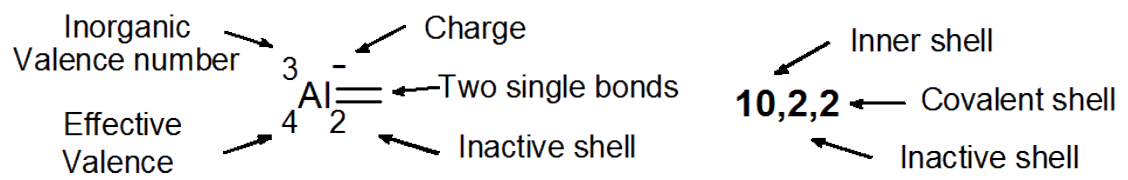

20 elements of the main group are inorganic. For the sake of illustration, only two of these are considered. Hydrogen $(\mathrm{H})$ has the least number of electrons of the main group and a valence number of 1 , whereas antimony $(\mathrm{Sb})$ has a higher 
number of electrons and a valence number of 5 .

For all states of these two elements, the even-odd rule is strictly applied in $\mathrm{Ta}$ ble 1 and Table 2 to calculate the different figures needed and the number of electrons in the different shells. In Table 1 and Table 2, the first row illustrates the positive state, the second row is the neutral state and the third is the negative state. Note that in both Table 1 and Table 2, the upper left number, the number of valence electrons, remains in all states equal to that from the periodic table.

As shown in Table 1 , the hydrogen atom has no electron in the inner shell, i.e. the first number $\mathbf{0}$ (in $\mathbf{0 , 0 , X}$ ) is applicable to every state (all three rows) of hydrogen. The second number, the number of electrons in the inactive shell, equals 2 (in $0,2,0$ ) only when hydrogen in a negative state is not bonded (third row).

Table 1. Hydrogen is inorganic with an empty inner shell whatever its state: a) $\mathrm{H}(+)$, obtained from $\mathrm{H} 2$ dissociation, is a free proton, b) neutral $\mathrm{H}$ in dihydrogen $\mathrm{H} 2$, c) $\mathrm{H}(-)$ forms an hydrogen bridge with two bonds, in $\mathrm{d}$ ) $\mathrm{H} 2$ is dissociated in $\mathrm{H}(-)$ as a complement of $\mathrm{H}(+)$.

\begin{tabular}{|c|c|c|c|c|c|c|c|}
\hline Hydrogen & 6 bonds & 5 bonds & 4 bonds & 3 bonds & 2 bonds & 1 bond & None \\
\hline $\begin{array}{c}\mathrm{H}(+) \\
0 \text { electron } \\
\text { Effective Valence: } 0 \\
\text { Proton Inorganic }\end{array}$ & & & & & & & $\begin{array}{l}{ }_{0}^{1}+ \\
0,0,0 \\
0\end{array}$ \\
\hline $\begin{array}{c}\mathrm{H} \\
1 \text { electron } \\
\text { Valence: } 1 \\
\text { Inorganic }\end{array}$ & & & & & & $\begin{array}{l}{ }_{1}^{1} \mathrm{H}_{0} \\
\mathbf{0 , 0 , 1} \text { b) }\end{array}$ & \\
\hline $\begin{array}{c}\mathrm{H}(-) \\
2 \text { electrons } \\
\text { Effective Valence: } 2 \\
\text { Inorganic }\end{array}$ & & & & & $\begin{array}{l}{ }_{2}^{1} \mathrm{H}_{0}^{-}- \\
\mathbf{0 , 0 , 2} \text { c) }\end{array}$ & & $\begin{array}{l}{ }_{2}^{1} \mathrm{H}_{2}^{-} \\
\mathbf{0 , 2 , 0} \text { d) }\end{array}$ \\
\hline
\end{tabular}

The third number gives the number of covalent bonds. It is 1 (in $0,0,1$ ) when for example a dihydrogen molecule forms by the association of two neutral hydrogen atoms (second row). In the third row, the hydrogen atom with 2 bonds is obtained when two atoms are bridged by the hydrogen in a negative state. In Table 1, H(+) cannot bond.

The second inorganic element chosen for illustration is antimony. It has 46 electrons in the inner shell and can be found in three possible states: positive in row 1 of Table 2 , neutral in row 2 and negative in row 3.

In Table 2, the very left neutral $\mathrm{Sb}$ has 5 bonds and is associated to the series $46,0,5$. 46 gives the number of electrons in the inner shell, 0 means no electrons in the inactive shell and 5 means that 5 electrons are involved in covalent bonds (i.e. the element is bonded to five distinct atoms). The addition of these numbers gives the total number of electrons (51) belonging to this element when in the neutral state.

Table 1 and Table 2 illustrate the main property of inorganic elements, i.e. the number of electrons in the inner shell of this element in a compound is constant and equal to the difference between the total number of electrons and the 
Table 2. Antimony is inorganic with 46 electrons in the inner shell whatever its state. In a) SbH4(+) [12] p557, b) SbCl2(+) [12] p561, c) Sb2 gas dissociation [12] p584. d) SbCl5 [12]. p553, e) SbCl3 [12] p558, f) NiSb [12]. p555, g) SbF6(-)[12]. p557-570, h) SbCl4(-) [12] p561 i) PH2(-) [12] p493, j) Sb2 gas dissociation [12] p584.

\begin{tabular}{|c|c|c|c|c|c|c|c|c|}
\hline Antimony & 6 bonds & 5 bonds & 4 bonds & & 3 bonds & 2 bonds & 1 bonds & none \\
\hline $\begin{array}{c}\mathrm{Sb}(+) \\
50 \text { elect. } \\
\text { Eff.Val: } 4 \\
\text { Inorganic }\end{array}$ & & & $\begin{array}{c}\stackrel{5}{4} \mathrm{Sb} \stackrel{+}{=} \\
46,0,4\end{array}$ & a) & & $\begin{array}{l}{ }_{4}^{5} \mathrm{Sb} \underset{2}{+} \\
\mathbf{4 6 , 2 , 2} \quad \text { b) }\end{array}$ & & $\begin{array}{r}{ }_{4}^{5} \mathrm{Sb}_{4}^{+} \\
\mathbf{4 6 , 4 , 0} \quad \text { c) }\end{array}$ \\
\hline $\begin{array}{c}\text { Sb } \\
\text { 51 elect. } \\
\text { Val: } 5 \\
\text { Inorganic }\end{array}$ & & $\begin{array}{c}\underset{5}{\equiv} \mathrm{Sb} \\
\mathbf{4 6 , 0 , 5}\end{array}$ & & & $\begin{array}{l}=\frac{5}{5} \mathrm{Sb}- \\
46,2,3 \quad \text { e) }\end{array}$ & & $\begin{array}{l}{ }_{5}^{5} \mathrm{Sb}- \\
\mathbf{4 6 , 4 , 1} \text { f) }\end{array}$ & \\
\hline $\begin{array}{c}\text { Sb(-) } \\
52 \text { elect. } \\
\text { Eff.Val: } 6 \\
\text { Inorganic }\end{array}$ & $\begin{array}{c}{ }_{6}^{5} \mathrm{Sb} \\
\mathbf{4 6 , 0 , 6}\end{array}$ & & $\begin{array}{c}\frac{5}{6} \mathrm{Sb}= \\
46,2,4\end{array}$ & h) & & $\begin{array}{l}{ }_{6}^{5} \mathrm{Sb}_{4}^{-}= \\
\mathbf{4 6 , 4 , 2} \text { i) }\end{array}$ & & $\begin{array}{l}{ }_{6}^{5} \mathrm{Sb}_{6}^{-} \\
\mathbf{4 6 , 6 , 0} \text { j) }\end{array}$ \\
\hline
\end{tabular}

valence number in the periodic table.

In the following chapters, organic or semi-organic elements are shown to have different behaviors.

\subsection{Organic Elements of the Main Group}

The main difference between inorganic and organic elements is the way electrons dispatch in the various electrons shells. Organic elements have indeed fewer electrons available to form covalent bonds than expected. In other words, the organic valence number, is lower than the valence number indicated in the periodic table. This is due to a transfer of electron pairs into the inner shell, which in turns contains more electrons than calculated from the periodic table.

The oxygen element (column 6) is taken below as an example to illustrate the group of organic elements. The highest observed number of bonds for neutral oxygen is two, as in $\mathrm{H} 2 \mathrm{O}$ [20]. If oxygen would behave like an inorganic element, it would be able to erect up to 6 bonds and create for example $\mathrm{H} 6 \mathrm{O}$, a molecule that has never been experimentally detected. Two electrons pairs have moved from the covalent shell of the atom into its inner shell. It makes them unavailable for covalent bonding.

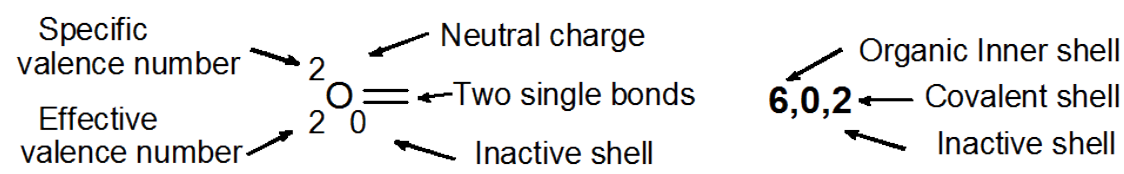

The organic valence number for oxygen in its neutral state is two, which means that it can only erect two bonds with other elements. The series of three numbers associated to neutral oxygen in $\mathrm{H} 2 \mathrm{O}$ is 6 (higher than in the periodic table), $\mathbf{0}$ (meaning no electrons is available for additional bonding) and 2 (for the two electrons already engaged in covalent bonding). 


\subsubsection{Three States for Organic Elements}

Unlike inorganic elements, the numbers of electrons in the inner shell of organic elements vary depending on their state:

- In a neutral state, some electrons pairs have moved into the inner shell and the organic valence number has the expected parity, albeit with a lower number of electrons pairs than calculated from the periodic table.

- In a positive state, an electrons pair moves out of the inner shell and the organic valence number counts an extra pair compared to the neutral state.

- In negative state, one electrons pair moves into the inner shell and the organic valence number counts one pair less than in the neutral state.

The parity and the highest possible number of bonds in each state are evaluated using the same procedure than for the inorganic element but starting with a lower organic valence number.

\subsubsection{Only Two Organic Elements with Three States}

Among elements of the main group of the periodic table, only two are organic. oxygen $(\mathrm{O})$ and fluorine $(\mathrm{F})$. They have more electrons pairs in their inner shells than expected from the periodic table.

Table 3 and Table 4 describe the different states and bonding configurations of respectively oxygen and fluorine. As illustrated in Table 3, the inner shell of oxygen contains 4, 6 or 8 electrons in its respectively positive, neutral or negative state. Electrons are thus fewer in the valence shell, which also means that fewer electrons are available to build covalent bonds. Consequently, the highest number of bonds oxygen can erect is 3 in the positive state, 2 in the neutral state and 1 in the negative state.

In the next tables, green colored cells mark organic states, i.e. configurations for which the inner shells contain more electrons than would be expected. Since oxygen and fluorine are fully organic, obviously, all cells are green.

On the right side of Table 3, the neutral monoatomic oxygen is known to be

Table 3. Oxygen is an organic element with 4, 6 and 8 electrons in the state dependent inner shell : a) $\mathrm{H3O}(+)[12]$ p625, b) $\mathrm{NO}(+)$ or $\mathrm{ClO}(+)$ [12] p835-6-7, c) H2O [12] p629, d) mono-atom O [12], e) $\mathrm{OH}(-)$ [12] p629.

\begin{tabular}{|c|c|c|c|c|c|c|c|}
\hline Oxygen & 6 bonds & 5 bonds & 4 bonds & 3 bonds & 2 bonds & 1 bond & none \\
\hline $\begin{array}{c}\mathrm{O}(+) \\
7 \text { electrons } \\
\text { Effective Valence: } 3 \\
\text { Organic }\end{array}$ & & & & $\begin{array}{l}\frac{4}{3} \mathrm{O}^{+}- \\
4,0,3 \text { a) }\end{array}$ & & $\begin{array}{l}{ }_{3}^{4} \mathrm{O}^{+}- \\
4,2,1 \text { b) }\end{array}$ & \\
\hline $\begin{array}{c}\text { O } \\
\text { 8 electrons } \\
\text { Effective Valence: } 2 \\
\text { Organic }\end{array}$ & & & & & $\begin{array}{l}2 \\
20 \\
20 \\
6,0,2 \text { c) }\end{array}$ & & $\begin{array}{l}2 \mathrm{O} \\
22 \\
6,2,0 \mathrm{~d}\end{array}$ \\
\hline $\begin{array}{c}\mathrm{O}(-) \\
9 \text { electrons } \\
\text { Effective Valence: } 1 \\
\text { Organic }\end{array}$ & & & & & & $\begin{array}{l}00- \\
10 \\
8,0,1\end{array}$ & \\
\hline
\end{tabular}


Table 4. Fluorine is an organic element with 6, 8 and 10 electrons in the state dependent inner shell : a) FH2(+) [12] p816, b) F2 dissociated, c) F2 gas -200, d) F2 dissociated [21].

\begin{tabular}{|c|c|c|c|c|c|c|c|}
\hline Fluorine & 6 bonds & 5 bonds & 4 bonds & 3 bonds & 1 bond & 1 bond & none \\
\hline $\begin{array}{c}\mathrm{F}(+) \\
8 \text { electrons } \\
\text { Effective Valence: } 2 \\
\text { Organic }\end{array}$ & & & & & $\begin{array}{l}{ }_{2}^{3} F^{+} \\
6,0,2 \\
\end{array}$ & & $\begin{array}{l}3+ \\
2^{3} 2 \\
6,2,0\end{array}$ \\
\hline $\begin{array}{c}\text { F } \\
9 \text { electrons } \\
\text { Valence: } 1 \\
\text { Organic }\end{array}$ & & & & & & $\begin{array}{l}{ }_{1}^{1} \mathrm{~F}- \\
\mathbf{8 , 0 , 1} \text { c) }\end{array}$ & \\
\hline $\begin{array}{c}\mathrm{F}(-) \\
10 \text { electrons } \\
\text { Effective Valence: } 0 \\
\text { Organic }\end{array}$ & & & & & & & $\begin{array}{l}{ }^{-1} \mathrm{~F}^{-} \\
\left.0^{10,0,0} \mathrm{~d}\right)\end{array}$ \\
\hline
\end{tabular}

very reactive [12]. This reactivity is compatible with the presence of an electrons pair in the inactive shell of this oxygen configuration.

The second organic element is fluorine. From the periodic table, F would be expected to have 2 electrons in its inner shell and 7 electrons in its outer shell. As shown in Table 4 however, fluorine in its neutral state has 8 electrons in its inner shell and one electron in its covalent shell. Only one covalent bond is possible in this state, like observed with the molecule HF.

For the other states, one pair is removed from the inner shell in $\mathrm{F}(+)$, and 1 pair is added to the inner shell for $\mathrm{F}(-)$. This last form cannot build any compound.

By comparing inorganic elements in Table 1 and Table 2 and organic elements in Table 3 and Table 4, one can see how important the influence of a charge is on the way electrons dispatch in the different shells. For organic elements, the more positive the charge, the higher the number of possible bonds. This is the opposite for inorganic elements for which there is a higher number of bonds possible when electrons are added.

The present study didn't identify other organic elements in the main group of the periodic table described in Ref. [12].

\subsection{Semi-Organic Elements}

Elements in this sub-group are inorganic in their negative states, i.e. with as many electrons in the inner shell as predicted by the periodic table, and organic in their positive states, i.e. with higher electrons in the inner shell than expected.

The semi-organic sub-group delineates like a boundary between the inorganic group and the organic group. The seven elements making this third sub-group are described in Tables 5-11.

Table 5 and Table 6 describe carbon and nitrogen, two elements in period 2 of the periodic table. In Table 7 and Table 8, sulfur and chlorine belong to period 3. In Table 9 and Table 10, selenium and bromine are in period 4. Iodine, in Table 11, is the only semi-organic element in period 5.

In all seven following Tables, inorganic states are marked in white (expected 
inner shell) and organic states are marked in green (different inner shell).

\subsubsection{Semi-Organic Elements from Period 2 of the Periodic Table}

In Table 5, carbon is shown with possible bonding configurations. In the periodic table, carbon has 6 electrons, 2 of which are supposed to be in the inner shell and 4 available for bonding. In the even-odd model, carbon in neutral and positive states (first and second row) is inorganic and the inner shell contains the expected number of electrons. In the third row, one electrons pair has moved into the inner shell and the highest number of bonds is lower than expected. The negative state is organic. Carbon can only build 3 bonds in this state, to form compounds like $\mathrm{CH} 3(-)$.

In Table 6, nitrogen is shown with possible bonding configurations. In the periodic table, nitrogen has 7 electrons, 2 of which are supposed to be in the inner shell and 5 available for bonding. In the upper row, the nitrogen in a positive state is inorganic and the inner shell contains the expected 2 electrons. In the

Table 5. Carbon is a semi-organic element. Its inner shell contains 2 electrons in the positive and neutral states whereas 4 electrons in the negative state. a) $\mathrm{C} 2 \mathrm{H} 6$ dissociation [15], b) $\mathrm{C} 2 \mathrm{H} 2$ dissociation [22], c) $\mathrm{CH} 4$ [12] p301, d) $\mathrm{HCN}$ [12] p320, e) C monoelement, f) C2H6 dissociation [15], g) $\mathrm{CN}(-)$ [12] p321.

\begin{tabular}{|c|c|c|c|c|c|c|c|}
\hline Carbon & 6 bonds & 5 bonds & 4 bonds & 3 bonds & 2 bonds & 1 bonds & none \\
\hline $\begin{array}{c}\mathrm{C}(+) \\
5 \text { electrons } \\
\text { Effective Valence: } 3 \\
\text { Inorganic }\end{array}$ & & & & $\begin{array}{l}=\stackrel{+}{C}+\frac{}{30} \\
2,0,3 \text { a) }\end{array}$ & & $\begin{array}{l}4+ \\
32 \\
2,2,1 \text { b) }\end{array}$ & \\
\hline $\begin{array}{c}\text { C } \\
6 \text { electrons } \\
\text { Valence: } 4 \\
\text { Inorganic }\end{array}$ & & & $\begin{array}{l}\stackrel{4}{=}= \\
2,0,4 \text { c) }\end{array}$ & & $\begin{array}{l}-4 \\
42- \\
2,2,2 \text { d) }\end{array}$ & & $\begin{array}{l}{ }^{4} \mathrm{C} \\
4{ }_{4} \\
\mathbf{2}, 4,0 \text { e) }\end{array}$ \\
\hline $\begin{array}{c}\mathrm{C}(-) \\
7 \text { electrons } \\
\text { Effective Valence: } 3 \\
\text { Organic }\end{array}$ & & & & $\begin{array}{l}2 \mathrm{C}^{-} \\
= \\
4,0,3 \mathrm{f}\end{array}$ & & $\begin{array}{l}{ }^{2} \mathrm{C}^{-}- \\
32 \\
4,2,1 \mathrm{~g})\end{array}$ & \\
\hline
\end{tabular}

Table 6. Nitrogen is a semi-organic element. Its inner shell contains 2 electrons in the positive states, 4 in the neutral state and 6 electrons in the negative state. a) NF4(+) [12] p439, b) N2F4 dissociate $\mathrm{NF}_{2}(+)$, c) N2 dissociation, d) NF3 [12] p439, e) N2 gas, f) $\mathrm{N} 2 \mathrm{~F} 4$ Dissociate NF2 $\left.(-) \sim-200^{\circ} \mathrm{C}, \mathrm{g}\right) \mathrm{N} 2$ dissociation.

\begin{tabular}{|c|c|c|c|c|c|c|c|}
\hline Nitrogen & 6 bonds & 5 bonds & 4 bonds & 3 bonds & 2 bonds & 1 bonds & none \\
\hline $\begin{array}{c}\mathrm{N}(+) \\
6 \text { electrons } \\
\text { Effective Valence: } 4 \\
\text { Inorganic }\end{array}$ & & & $\begin{array}{l}5+ \\
=\mathrm{N}= \\
\mathbf{2 , 0 , 4} \\
=\end{array}$ & & $\begin{array}{l}5+ \\
-\mathrm{N}- \\
2,2,2 \mathrm{~b})\end{array}$ & & $\begin{array}{l}5+ \\
{ }^{5}+ \\
2,4,0 \\
\text { c) }\end{array}$ \\
\hline $\begin{array}{c}\mathrm{N} \\
7 \text { electrons } \\
\text { Effective Valence: } 3 \\
\text { Organic }\end{array}$ & & & & $\begin{array}{l}\stackrel{3}{=} \mathrm{N}- \\
\begin{array}{l}30 \\
\mathbf{4 , 0 , 3}\end{array}\end{array}$ & & $\begin{array}{l}{ }_{3}^{3}- \\
4,2,1 \text { e) }\end{array}$ & \\
\hline $\begin{array}{c}\mathrm{N}(-) \\
\mathbf{8} \text { electrons } \\
\text { Effective Valence: } \mathbf{2} \\
\text { Organic }\end{array}$ & & & & & $\begin{array}{l}{ }^{1} \mathrm{~N}- \\
20 \\
6,0,2 \mathrm{f}\end{array}$ & & $\begin{array}{l}{ }^{1} \mathrm{~N}^{-} \\
2^{2} \\
6,2,0 \mathrm{~g})\end{array}$ \\
\hline
\end{tabular}


other rows, electrons pairs have moved into the inner shell and the highest number of bonds is lower than expected. The nitrogen contains 4 inner-shell electrons in a neutral state, whereas it contains 6 electrons in a negative state. In the latter, fewer electrons are available to build covalent bonds, hence the lower number of possible bonds. Neutral nitrogen can build 1 or 3 bonds, while it can only have 2 or 0 bonds in its negative state.

\subsubsection{Semi-Organic Elements from Period 3 of the Periodic Table}

In the third period, the semi-organic pair of elements is sulfur and chlorine. They can be found in column 6 and 7 of the periodic table. S(+) and S are inorganic, while $\mathrm{S}(-)$ is organic. The second, further right, has only one inorganic state $\mathrm{Cl}(+)$ and two organic states, $\mathrm{Cl}$ and $\mathrm{Cl}(-)$. This pair is described in Table 7 and Table 8.

Table 7. Sulfur is a semi-organic element. Its inner shell contains 10 electrons in the positive and neutral states whereas 12 electrons in the negative state. a) S2F10 dissociation [12] p663, b) SF3(+) [12] p663, c) S2F2 dissociation [12] p684, d) SF6 [12] p663, e) SF4 [12] p663, f) H2S [12] p663, g) Sulfur mono-element, h) S2F10 dissociation [12] p663, i) SF3(-) not found, j) SH(-) [12] p682.

\begin{tabular}{|c|c|c|c|c|c|c|c|}
\hline Sulfur & 6 bonds & 5 bonds & 4 bonds & 3 bonds & 2 bonds & 1 bonds & none \\
\hline $\begin{array}{c}\mathrm{S}(+) \\
15 \text { electrons } \\
\text { Effective Valence: } 5 \\
\text { Inorganic }\end{array}$ & & $\begin{array}{l}\frac{6}{5} S \stackrel{+}{=} \\
= \\
10,0,5 \text { a) }\end{array}$ & & $\begin{array}{l}6+ \\
=5 S^{+} \\
10,2,3 \mathrm{~b})\end{array}$ & & $\begin{array}{l}6+ \\
54 \\
10,4,1 \text { c) }\end{array}$ & \\
\hline $\begin{array}{c}S \\
16 \text { electrons } \\
\text { Valence: } 6 \\
\text { Inorganic }\end{array}$ & $\begin{array}{l}{ }_{6}^{6} \mathrm{~S} \equiv \\
\overline{10,0,6} \mathrm{~d})\end{array}$ & & $\begin{array}{l}\frac{6}{6} \mathrm{~S}= \\
\mathbf{1 0 , 2 , 4} \mathrm{e})\end{array}$ & & $\begin{array}{l}6 \\
-54 \\
10,4,2 \text { f) }\end{array}$ & & $\begin{array}{l}6 \\
6 S_{6} \\
10,6,0 \mathrm{~g})\end{array}$ \\
\hline $\begin{array}{c}\text { S(-) } \\
17 \text { electrons } \\
\text { Effective Valence: } 5 \\
\text { Organic }\end{array}$ & & $\begin{array}{l}\frac{4}{\equiv} S^{-}= \\
= \\
12,0,5 \\
\end{array}$ & & $\begin{array}{l}\frac{4}{5} \mathrm{~S}- \\
12,2,3 \mathrm{i})\end{array}$ & & $\begin{array}{l}{ }_{5}^{4} \mathrm{~S}^{-}- \\
12,4,1 \mathrm{j})\end{array}$ & \\
\hline
\end{tabular}

Table 8. Chlorine is a semi-organic element. Its inner shell contains 10 electrons in the positive state, 12 electrons in the neutral state and 14 electrons in the negative state. a) ClF6(+) [12] p839, b) ClF4(+) [12] p834, c) ClF2(+) [12] p830, d) Cl2 dissociation [12] p806, e) ClF5 [12] p832, f) ClF3 [12] p825, g) Cl2 $\mathrm{HCl}$ [12] p806, h) ClF4(-) [12] p830, i) ClF2(-) [12] p827, j) Cl2 dissociation [12] p806.

\begin{tabular}{|c|c|c|c|c|c|c|c|}
\hline Chlorine & 6 bonds & 5 bonds & 4 bonds & 3 bonds & 2 bonds & 1 bonds & none \\
\hline $\begin{array}{c}\mathrm{Cl}(+) \\
16 \text { electrons } \\
\text { Effective Valence: } 6 \\
\text { Inorganic }\end{array}$ & 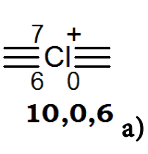 & & $\begin{array}{l}\frac{7}{6} \mathrm{Cl}= \\
\mathbf{1 0 , 2 , 4} \mathrm{b})\end{array}$ & & $\begin{array}{l}-7+ \\
6 \mathrm{Cl}- \\
10,4,2 \text { c) }\end{array}$ & & $\begin{array}{l}7 \mathrm{Cl}^{+} \\
6{ }_{6} \\
10,6,0 \mathrm{~d})\end{array}$ \\
\hline $\begin{array}{c}\mathrm{Cl} \\
17 \text { electrons } \\
\text { Valence : } 5 \\
\text { Organic }\end{array}$ & & 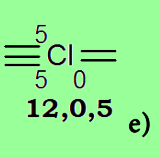 & & $\begin{array}{l}\frac{5}{5} \mathrm{Cl}- \\
12,2,3 \mathrm{f})\end{array}$ & & $\begin{array}{l}{ }_{5}^{5} \mathrm{Cl}- \\
12,4,1 \mathrm{~g})\end{array}$ & \\
\hline $\begin{array}{c}\mathrm{Cl}(-) \\
18 \text { electrons } \\
\text { Effective Valence: } 4 \\
\text { Organic }\end{array}$ & & & $\begin{array}{l}\stackrel{3}{=} \mathrm{Cl}_{0}^{-} \\
= \\
\mathbf{1 4 , 0 , 4} \mathrm{h})\end{array}$ & & $\begin{array}{l}\frac{3}{4} \mathrm{Cl}_{2}^{-} \\
14,2,2 \text { i) }\end{array}$ & & $\begin{array}{l}{ }_{4}^{3} \mathrm{Cl}_{4}^{-} \\
14,4,0 \text { j) }\end{array}$ \\
\hline
\end{tabular}


In its neutral state, sulfur has a valence number of 6 and its inner shell contains 10 electrons. It can erect an even number of bonds from 0 to 6 , as in the well-known SF6 (row 2 in Table 7). In the lower row, $\mathrm{S}(-)$ is organic. Its inner shell contains an additional electrons pair compared to the neutral and positive states. The highest number of bonds in this state is lower than in the other states. SF5(-), obtained by a dissociation of S2F10, is a good representative of this row, in which sulfur can build 1 to 5 bonds.

Chlorine, shown in Table 8, is the second semi-organic element of this period. It is located further right in the periodic table and has one inorganic state and two organic states. The inner shells of neutral $\mathrm{Cl}$ and $\mathrm{Cl}(-)$ respectively contain 12 and 14 electrons. The higher number of bonds for these states is reduced: $\mathrm{ClF} 5$ and $\mathrm{ClF} 4(-)$ are representative compounds of these states.

\subsubsection{Semi-Organic Elements in Period 4 of the Periodic Table}

Selenium and bromine compose the pair of semi-organic elements in period 4 of

Table 9. Selenium is a semi-organic element. Its inner shell contains 28 electrons in the positive and neutral states and 30 electrons in the negative state. Same references than for Sulfur [12].

\begin{tabular}{|c|c|c|c|c|c|c|c|}
\hline Selenium & 6 bonds & 5 bonds & 4 bonds & 3 bonds & 2 bonds & 1 bond & none \\
\hline $\begin{array}{c}\mathrm{Se}(+) \\
33 \text { electrons } \\
\text { Effective Valence: } 5 \\
\text { Inorganic }\end{array}$ & & $\underset{5}{\stackrel{6}{=}} \mathrm{Se}_{0}^{+}=$ & & $\begin{array}{c}6 \\
= \\
= \\
28,2 \\
28,2,3\end{array}$ & & $\begin{array}{c}6 \mathrm{Se} \\
5{ }^{4} \\
\mathbf{2 8 , 4 , 1}\end{array}$ & \\
\hline $\begin{array}{c}\mathrm{Se} \\
\text { 34 electrons } \\
\text { Valence: } 6 \\
\text { Inorganic }\end{array}$ & $\begin{array}{c}{ }_{6}^{6} \\
\mathbf{2 8 , 0 , 6}\end{array}$ & & $\underset{6}{=} \mathrm{Se}=$ & & $\begin{array}{c}6 \\
-\mathrm{Se}- \\
6{ }^{4} \\
\mathbf{2 8 , 4 , 2}\end{array}$ & & $\begin{array}{l}{ }^{6} \mathrm{Se} \\
6 \quad 6 \\
\mathbf{2 8 , 6 , 0}\end{array}$ \\
\hline $\begin{array}{c}\operatorname{Se}(-) \\
35 \text { electrons } \\
\text { Effective Valence: } 5 \\
\text { Organic }\end{array}$ & & $\begin{array}{c}\underset{5}{\equiv} \mathrm{Se}_{0}^{-}= \\
\mathbf{3 0 , 0 , 5}\end{array}$ & & $\begin{array}{c}\frac{4}{5} \mathrm{Se}_{2}^{-} \\
30,2,3\end{array}$ & & $\begin{array}{l}{ }_{5}^{4} \mathrm{Se}_{4}^{-} \\
30,4,1\end{array}$ & \\
\hline
\end{tabular}

Table 10. Bromine is a semi-organic element. Its inner shell contains 28 electrons in the positive state, 30 electrons in the neutral state and 32 electrons in the negative state. Same references than for Chlorine [12].

\begin{tabular}{|c|c|c|c|c|c|c|c|}
\hline Bromine & 6 bonds & 5 bonds & 4 bonds & 3 bonds & 2 bonds & 1 bonds & none \\
\hline $\begin{array}{c}\mathrm{Br}(+) \\
\text { 34 electrons } \\
\text { Effective Valence: } 6 \\
\text { Inorganic }\end{array}$ & $\begin{array}{c}\underset{6}{\overline{2}} \mathrm{Br} \\
\mathbf{2 8 , 0 , 6}\end{array}$ & & $\begin{array}{c}\frac{7}{6} \mathrm{Br}= \\
28,2,4\end{array}$ & & $\begin{array}{c}7 \underset{+}{7} \mathrm{Br}- \\
64 \\
\mathbf{2 8 , 4 , 2}\end{array}$ & & $\begin{array}{l}7 \mathrm{Br}^{+} \\
6{ }_{6} \\
\mathbf{2 8 , 6 , 0}\end{array}$ \\
\hline $\begin{array}{c}\mathrm{Br} \\
35 \text { electrons } \\
\text { Valence : } 5 \\
\text { Organic }\end{array}$ & & $\begin{array}{l}{ }_{5}^{5} \\
\end{array} \mathrm{rr}=$ & & $\begin{array}{c}\frac{5}{5} \mathrm{Br} \\
= \\
30,2,3\end{array}$ & & $\begin{array}{l}{ }_{5}^{5} \mathrm{Br} \\
5 \\
30,4,1\end{array}$ & \\
\hline $\begin{array}{c}\mathrm{Br}(-) \\
36 \text { electrons } \\
\text { Effective Valence: } 4 \\
\text { Organic }\end{array}$ & & & $\begin{array}{l}\frac{3}{4} \mathrm{Br}= \\
32,0,4\end{array}$ & & $\begin{array}{l}3{ }^{-}- \\
4 r_{2} \\
32,2,2\end{array}$ & & $\begin{array}{l}3 \mathrm{Br}^{-} \\
4^{-} 4 \\
32,4,0\end{array}$ \\
\hline
\end{tabular}


the periodic table. They are found in columns 6 and 7 in the main group of the periodic table. The first has two inorganic states, $\mathrm{Se}(+)$ and neutral Se and one inorganic state $\mathrm{Sr}(-)$. The second has only one inorganic state, $\mathrm{Br}(+)$, and two are organic in neutral $\mathrm{Br}$ and $\mathrm{Br}(-)$. This pair is illustrated in Table 9 and Table 10 and they have the same properties than the elements previously described in Table 7 and Table 8.

\subsubsection{Semi-Organic Elements in Period 5 of the Periodic Table}

Iodine and xenon compose the pair of semi-organic elements in period 5 of the periodic table. They are found in columns 7 and 8 . The first has two inorganic states $\mathrm{I}(+)$ and neutral I, and one organic in $\mathrm{I}(-)$. The second is a rare gas not included in this paper. Table 11 describes iodine which inner shell contains 46 electrons as shown in the two first rows.

In Table 11, the last row is green to highlight the organic $\mathrm{I}(-)$. There are 48 electrons in this inner shell and the highest number of bonds is 6, like in IF6(-). Iodine cannot build 8 bonds as would be expected if it were inorganic, as revealed by the absence of references to compounds like for example IF8(-).

Table 11. Iodine is a semi-organic element. Its inner shell contains 46 electrons in the positive and neutral states whereas 48 electrons in the negative state. a) IF6(+) [12] p839, b) IF4(+) [12] p839, c) IF2(+) [12] p839, d) I2 dissociation, e) IF7 [12] p838, f) IF5 [12] p842, g) I2O5 [12] p853, h) I2 gas, i) [12] p875, j) to be found, k) IF2(-) [12] p836, l) I2 dissociation.

\begin{tabular}{|c|c|c|c|c|c|c|c|c|}
\hline Iodine & 7 bonds & 6 bonds & 5 bonds & 4 bonds & 3 bonds & 2 bonds & 1 bonds & none \\
\hline $\begin{array}{c}\mathrm{I}(+) \\
52 \text { electrons } \\
\text { Effec. Valen: } 6 \\
\text { Inorganic }\end{array}$ & & 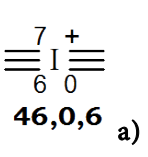 & & $\begin{array}{l}=\frac{7}{6} \mathrm{I} \stackrel{+}{=} \\
\mathbf{4 6 , 2 , 4} \text { b) }\end{array}$ & & $\begin{array}{l}{ }_{6}^{7} \mathrm{I} \\
\mathbf{4 6 , 4 , 2} \text { c) }\end{array}$ & & $\begin{array}{c}7{ }_{\mathrm{I}}^{+} \\
66,6,0 \mathrm{~d}\end{array}$ \\
\hline $\begin{array}{c}\text { I } \\
53 \text { electrons } \\
\text { Valence : } 7 \\
\text { Organic }\end{array}$ & $\begin{array}{l}\sum_{7}^{7} \\
\text { I6,0,7 e) }\end{array}$ & & $\begin{array}{l}\frac{7}{\overline{7}} \mathrm{I}= \\
46,2,5 \mathrm{f})\end{array}$ & & $\begin{array}{l}=\frac{7}{7} \mathrm{I} \\
\mathbf{4 6 , 4 , 3} \mathrm{g})\end{array}$ & & $\begin{array}{l}{ }_{7}^{7} \mathrm{I} \\
\mathbf{4 6 , 6 , 1} \mathrm{h})\end{array}$ & \\
\hline $\begin{array}{c}\text { I(-) } \\
54 \text { electrons } \\
\text { Effec. Valen:6 } \\
\text { Organic }\end{array}$ & & $\begin{array}{l}\bar{\equiv}_{6}^{5} \mathrm{I} \\
\overline{48,0,6}\end{array}$ & & $\begin{array}{l}=\frac{5}{6} \mathrm{I} \\
\mathbf{4 8 , 2 , 4} \mathrm{j})\end{array}$ & & $\begin{array}{l}5 \bar{I} \overline{\overline{4}} \\
\mathbf{4 8 , 4 , 2} \mathbf{k})\end{array}$ & & $\begin{array}{c}{ }^{5}{ }^{-} \\
68 \\
\mathbf{4 8 , 6 , 0}\end{array}$ \\
\hline
\end{tabular}

\section{Discussion}

\subsection{Evolution of the Even-Odd Rule}

Throughout this study, Greenwood Ref. [12] was used as the main source for formulas of experimentally observed compounds. At first, the author observed regularity within the 5 first periods in the main group of elements of the periodic table: on the left of the table, elements seem able to build all bonds made possible by their valence number. Further into the period however, elements seem less able to form compounds involving many bonds. The classical answer to that problem, multiple bonds, is not in reach. With our set constraint given by the even-odd rule that atoms can only build single bonds associated to a variability in the number of electrons in the inner shell is an alternative hypothesis to ex- 
plain this pattern.

\subsection{Progressive Aspect between Inorganic and Organic}

In the above paragraphs, (Tables 5-11), one pair of adjacent semi-organic elements can be found in each period of the periodic table. One can see it as a progression from left to right, between inorganic and semi-organic to fully organic. At the beginning of periods, elements are inorganic. Further into the period, a first semi-organic element is found, one with two inorganic states, then the next one with only one inorganic state. To the right of the table, elements are fully organic.

\subsection{On the Definition of Organic Compounds}

There is a common understanding in science to distinguish organic from inorganic compounds. The difference is particularly well defined when comparing large biological [23] and geological specimens [24]. When talking of small compounds however, the distinction is less clear. Even widely recognized references do not try to describe differences between organic and inorganic compounds [12], [25], [26]. To define organic compounds, the main argument gravitates around the presence of hydrocarbon endings. Even this definition is somewhat arbitrary [27].

In this paper, a clear and simple definition is given to distinguish between organic and inorganic elements. The difference comes from the number of electrons in the inner shell. In the main group of elements, the 20 inorganic elements keep the number of electrons in their inner shell as expected in the period: see hydrogen and antimony described above. By opposition, organic elements have a higher number of electrons in their inner shell than expected from their row of the periodic table. As an example, oxygen inner-shell contains more than two electrons in this shell. Furthermore, the charge state of organic elements also influences the number of electrons in the inner shell: positive fluorine, neutral fluorine and negative fluorine have respectively 6,8 or 10 electrons in the inner shell.

Based on this understanding, the present paper proposes to consider that the term organic is affected to one chemical element when the number of electrons in the inner shell is higher than expected from the periodic table. The author also proposes to extend the designation organic to any compounds containing at least one organic state of one element.

\section{Conclusion}

The even-odd rule is meant to explain how electrons dispatch into the electrons shells, when an atom is bonded to other atoms in a compound. Electrons in the inner shell are not available for bonding, whereas electrons in the covalent shell are already involved in bonds. The other electrons are in the inactive shell and as such, ready to build new bonds with additional atoms. In the present paper, an alternative definition of organic matter is introduced. Inorganic elements have 
the faculty to keep a constant inner shell and can build as many bonds as per their valence number, indicated in the periodic table. Organic elements however, can build fewer bonds than one could assume from their valence number. This peculiarity is due to a transfer of electrons pairs into the inner shell, where they cannot interconnect. A progression is observed in the periodic table of elements, with pairs of semi-organic elements found at the interface between the group of inorganic elements and the group of organic elements. For these elements, the number of electrons in the inner shell is charge dependent, which also means that they can build fewer bonds in some cases. Oxygen and fluorine are the only fully organic elements in the main group of elements, while $\mathrm{C}, \mathrm{N}, \mathrm{S}, \mathrm{Cl}, \mathrm{Se}, \mathrm{Br}$ and I count as semi-organic. The difference in behavior between organic and inorganic elements explains why there were fewer compounds observed than originally predicted by the even-odd rule.

\section{Acknowledgements}

The author wishes to thank Marine Auvert for her fruitful discussions and critical reading to reformulate this paper.

\section{References}

[1] Abegg, R. (1904) Die Valenz und das periodische System. Zeitschrift für anorganische Chemie, 39, 330-380. https://doi.org/10.1002/zaac.19040390125

[2] Lewis, G.N. (1916) The Atom and the Molecule. Journal of the American Chemical Society, 38, 762-785. https://doi.org/10.1021/ja02261a002

[3] Langmuir, I. (1919) The Arrangement of Electrons in Atoms and Molecules. Journal of the American Chemical Society, 41, 868-934. https://doi.org/10.1021/ja02227a002

[4] Kekulé, A. (1865) Sur la constitution des substances aromatiques. Bulletin de la Société Chimique de Paris, 3-2, 98-110.

[5] Couper, A.S. (1858) Sur une nouvelle théorie chimique. Annales de Chimie et de Physique, 53, 469-489.

[6] Gillespie, R.J. (2004) Teaching Molecular Geometry with the VSEPR Model. Journal of Chemical Education, 81, 298-304. https://doi.org/10.1021/ed081p298

[7] Gillespie, R.J. and Popelier, P.L.A. (2001) Chemical Bonding and Molecular Geometry: From Lewis to Electron Densities. Oxford University Press, Oxford.

[8] Auvert, G. (2014) Improvement of the Lewis-Abegg-Octet Rule Using an "EvenOdd" Rule in Chemical Structural Formulas: Application to Hypo and Hyper-Valences of Stable Uncharged Gaseous Single-Bonded Molecules with Main Group Elements. Open Journal of Physical Chemistry, 4, 60-66. https://doi.org/10.4236/ojpc.2014.42009

[9] Auvert, G. (2014) Chemical Structural Formulas of Single-Bonded Ions Using the “Even-Odd” Rule Encompassing Lewis's Octet Rule: Application to Position of Single-Charge and Electron-Pairs in Hypo- and Hyper-Valent Ions with Main Group Elements. Open Journal of Physical Chemistry, 4, 67-72. https://doi.org/10.4236/ojpc.2014.42010

[10] Auvert, G. (2014) The Even-Odd Rule on Single Covalent-Bonded Structural Formulas as a Modification of Classical Structural Formulas of Multiple-Bonded Ions 
and Molecules. Open Journal of Physical Chemistry, 4, 173-184.

https://doi.org/10.4236/ojpc.2014.44020

[11] Auvert, G. (2015) How the Even-Odd Rule, by Defining Electrons Pairs and Charge Positions, Can Be Used as a Substitute to the Langmuir-Octet Rule in Understanding Interconnections between Atoms in Ions and Molecules. Open Journal of Physical Chemistry, 5, 28-38. https://doi.org/10.4236/ojpc.2015.52004

[12] Greenwood, N.N. and Earnshaw, A. (1998) Chemistry of the Elements. 2nd Edition, Butterworth-Heinemann, Oxford.

[13] Wells, A.F. (1962) Structural Inorganic Chemistry. 3rd Edition, Clarendon Press, Oxford.

[14] Haynes, W. (2012) Handbook of Chemistry and Physics. 96th Edition, CRC Press, Boca Raton.

[15] http://en.wikipedia.org/wiki/

[16] Mendelejew, D. (1869) Über die Beziehungen der Eigenschaften zu den Atomgewichten der Elemente. Zeitschrift für Chemie, 12, 405-406. (In German)

[17] Auvert, G. and Auvert, M. (2015) Chemical Bonds between Charged Atoms in the Even-Odd Rule and a Limitation to Eight Covalent Bonds per Atom in CenteredCubic and Single Face-Centered-Cubic Crystals. Open Journal of Physical Chemistry, 5, 93-105. https://doi.org/10.4236/ojpc.2015.54010

[18] Auvert, G. and Auvert, M. (2016) The Even-Odd and the Isoelectronicity Rules Applied to Single Covalent Bonds in Ionic, Double-Face-Centered Cubic and Diamond-Like Crystals. Open Journal of Physical Chemistry, 6, 21-33. https://doi.org/10.4236/ojpc.2016.62002

[19] ACD/ChemSketch (2015) Advanced Chemistry Development, Inc., Toronto. http://www.acdlabs.com/

[20] Campbell, N.A., Williamson, B. and Heyden, R.J. (2006) Biology: Exploring Life. Pearson Prentice Hall, Boston.

[21] Kerr, J.A. (1992) Binary Dissociation. In: Handbook of Chemistry and Physics, 73rd Edition, CRC Press, Boca Raton, 9.129-9.137.

[22] https://en.wikipedia.org/wiki/Methylidyne_radical

[23] https://en.wikipedia.org/wiki/Biology

[24] https://en.wikipedia.org/wiki/Geology

[25] Holleman, A.F. and Wiberg, E. (2001) Inorganic Chemistry. Academic Press, San Francisco.

[26] Cotton, F.A. and Wilkinson, G. (1988) Advanced Inorganic Chemistry. 5th Edition, Wiley-Interscience, New York.

[27] https://en.wikipedia.org/wiki/Inorganic_chemistry 
Submit or recommend next manuscript to SCIRP and we will provide best service for you:

Accepting pre-submission inquiries through Email, Facebook, LinkedIn, Twitter, etc. A wide selection of journals (inclusive of 9 subjects, more than 200 journals)

Providing 24-hour high-quality service

User-friendly online submission system

Fair and swift peer-review system

Efficient typesetting and proofreading procedure

Display of the result of downloads and visits, as well as the number of cited articles Maximum dissemination of your research work

Submit your manuscript at: http://papersubmission.scirp.org/

Or contact ojpc@scirp.org 